\title{
RESEARCH NOTE \\ The influence of selected winemaking equipment and operations on the concentration of dissolved oxygen in wines
}

\author{
Juan F. Calderón', María del Alamo-Sanza², Ignacio Nevares² ${ }^{2}$ and V. Felipe \\ Laurie \\ ${ }^{1}$ Viña Casa Silva. El Bosque Sur Int. 77, Las Condes, Santiago, Chile. \\ ${ }^{2}$ UVaMOX, Escuela Técnica Superior de Ingenierías Agrarias, Universidad de Valladolid. Av. de Madrid, \\ 57, 34004 Palencia, Spain. \\ ${ }^{3}$ Facultad de Ciencias Agrarias, Universidad de Talca. 2 Norte 685 Talca, Chile.
}

\begin{abstract}
J.F. Calderón, M. del Alamo-Sanza, I. Nevares, and V.F. Laurie. 2014. The influence of selected winemaking equipment and operations on the concentration of dissolved oxygen in wines. Cien. Inv. Agr. 41(2): 273-280. Oxygen has a determining effect on the quality and longevity of wines. In spite of its importance, there are only a limited number of reports examining the levels of dissolved oxygen during wine production and the enrichments produced by different operations. In this study, the contribution of selected winemaking equipment and operations (i.e., pumping, centrifugation, tartrate stabilization, filtration and bulk wine transportation) on the concentration of dissolved oxygen in wines was assessed using a photoluminescence-based oxygen meter. For example, winemaking equipment such as diatomaceous earth filtration and membrane filtration caused dissolved oxygen increases between 0.100 and $0.200 \mathrm{mg} \mathrm{L}^{-1}$, and pad filtration and centrifugation showed average oxygen enrichments of approximately $0.350 \mathrm{mg} \mathrm{L}^{-1}$. However, operations such as filtration with rotary vacuum equipment and continuous tartrate stabilization produced oxygen enrichments up to $\sim 2.8 \mathrm{mg} \mathrm{L}^{-1}$. A better awareness of the levels of oxygen incorporated by different winemaking practices will help incorporate the necessary safeguards to protect wines from oxidation and estimate the magnitude of the cumulative exposure to oxygen during winemaking.
\end{abstract}

Key words: Dissolved oxygen, photoluminescence, oxygen meter, wine

\section{Introduction}

Oxygen exposure can have a positive or negative influence on the quality of wines. Once dissolved, oxygen is key to the growth and survival of wine microbes, as well as to a series of chemical reactions that may affect the stability, sensory features

Received February 20, 2014. Accepted June 21, 2014. Corresponding author: flaurie@utalca.cl and longevity of the product (Singleton, 1987; Danilewicz, 2003; Waterhouse and Laurie, 2006).

The main route of oxygen dissolution in musts or wines results from the direct contact with atmospheric air, a recurring situation that is exacerbated with mixing or turbulent flow. The solubility of oxygen in musts and wines also depends upon factors such as temperature, atmospheric pressure, ethanol concentration, and the presence 
of particles suspended in the liquid (Laurie and Clark, 2010).

Currently, the levels of dissolved oxygen (DO) in wines are a major concern during bottling and operations such as micro-oxygenation, but its routine determination at different points during the winemaking process by means of sensitive oxygen devices is not common. In fact, there are only a limited number of technical reports (Vidal et al., 2001, 2003 and 2004) and peer-reviewed papers in which wine DO levels during different stages of the process have been surveyed (Castellari et al., 2004). In most of these cases, the DO determinations were performed with traditional electrochemical-based oxygen meters.

Given the importance of oxygen in wine production and the scarcity of information regarding oxygen levels, the aim of this study was to evaluate the effects of selected winemaking equipment and processes on the content of DO in wines, measured in-line with a sensitive and minimally invasive photoluminescence-based oxygen meter.

\section{Materials and methods}

\section{Instrument for DO measurements}

DO was measured using a photoluminescencebased oxygen analyzer, 3 LCD Trace Fibox v7 (NomaSens GmbH, Regensburg, Germany), which allows the quantification of oxygen in a minimally invasive and nondestructive way by performing the measurements from the outside of a glass wall, as further explained below.

The oxygen sensors selected were the Oxi-trace PSt6 type (NomaSens GmbH, Regensburg, Germany) with a diameter of $10 \mathrm{~mm}$. These sensors have a measurement range of 0 to 1.8 $\mathrm{mg} \mathrm{L}^{-1}$ of dissolved oxygen. The sensors were glued to the inner wall of six sight-glass fittings using food-grade silicone, allowing them to be in contact with the wine while allowing the optical fiber of the DO meter to illuminate the sensor from the exterior of the glass (Figure 1). Once illuminated, the excitation of the sensor generates a response proportional to the amount of DO around the sensor.

To check the zero calibration of the sensors, they were periodically placed under a nitrogen gas atmosphere (Indura, 99.5\% purity). Regarding the frequency of the measurements, the analyzer was scheduled to deliver a beam of light (i.e., a measurement) every three seconds.

Surveyed wine types and winemaking operations

The wines in which the oxygen measurements were conducted were red and white monovarietals of Sauvignon blanc, Chardonnay, Cabernet

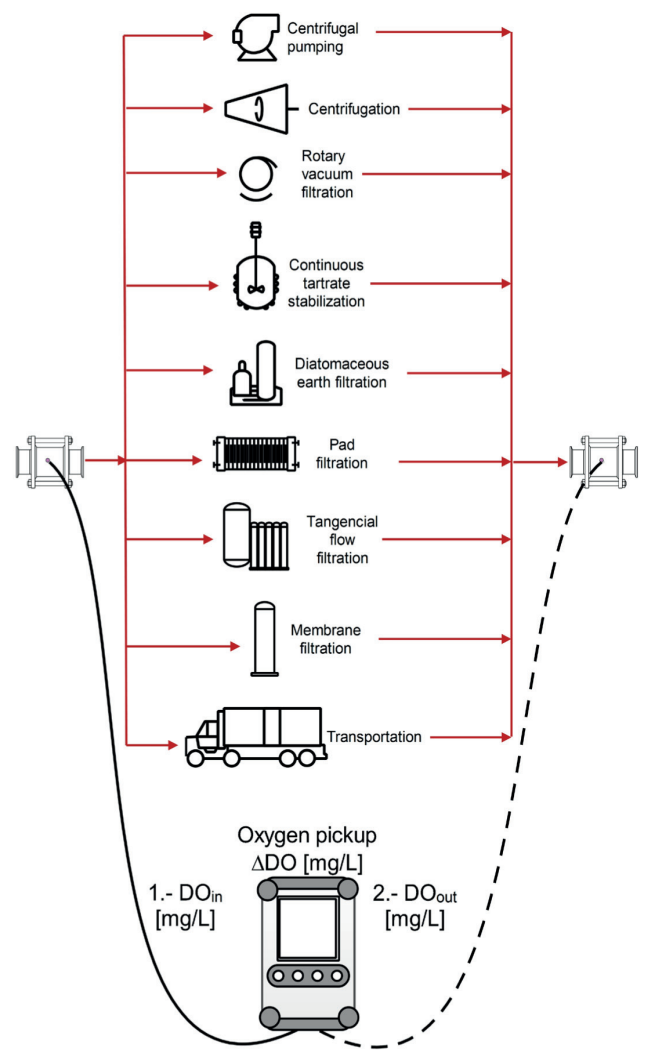

Figure 1. Schematic representation of the system for inline measurements of DO, with measurement points at the inlet and outlet of each winery operation. Note that the drawing is not to scale. 
Sauvignon and Carménère, as further detailed below. All wines were dry (had sugar concentrations $<2 \mathrm{~g} \mathrm{~L}^{-1}$ ), microbiologically stable, and had sulfite concentrations varying between 30 and 40 $\mathrm{mg} \mathrm{L}^{-1}$ of free $\mathrm{SO}_{2}$ and 80 to $140 \mathrm{mg} \mathrm{L}^{-1}$ of total $\mathrm{SO}_{2}$, as measured by aeration-oxidation (Ough and Amerine, 1988). The temperatures of the studied wines are detailed below. In all cases, the DO concentration before the use of the selected equipment (or processes) was below $0.180 \mathrm{mg} \mathrm{L}^{-1}$, and unless stated otherwise, the turbidity of the wines was below 140 NTU.

All measurements were conducted under normal operating conditions, without any other intervention but the installation of glass-sight fittings on the inlet and outlet of the winery equipment (or process) being tested. These measurements were performed during the continuous operation of the equipment after all pipes and parts had been filled with wine to avoid contamination with atmospheric air.

The oxygen contribution of each apparatus (process) examined was calculated by the DO difference between the inlet and outlet points. Moreover, for each of the operations tested, 10 different wines were evaluated, and 20 alternating measurements of one minute each between the inlet and outlet points were performed with a five-minute recess between them. In the case of centrifugal pumps, 20 different wines were evaluated.

The winery equipment and operations tested were as follows:

a) Centrifugal pumping: Three pumps of the same brand, model and average yield $(25,000 \mathrm{~L}$ $\mathrm{h}^{-1}$ ) (Della Toffola, model 2CV300, Italy) were assessed while racking 20 different finished white wines. The temperatures of the wines evaluated were between 11 and $11.6^{\circ} \mathrm{C}$.

b) Centrifugation: A GSC-15-06-177 separator (GEA Westfalia, Netherlands) of $8,000 \mathrm{~L} \mathrm{~h}^{-1}$ was tested while centrifuging red wines with approxi- mately 300 NTU and temperatures between 11.1 and $12.5^{\circ} \mathrm{C}$.

c) Rotary vacuum filtration: DO enrichment was evaluated on an $80 \mathrm{~m}^{2}$ vacuum filter (Della Toffola, Italy) operating with a pre-coat based on perlite during the filtration of red wines with a high content of solids and temperatures between 12 and $14{ }^{\circ} \mathrm{C}$.

d) Continuous tartrate stabilization (Velo, Italy. Nominal yield of $15,000 \mathrm{~L} \mathrm{~h}^{-1}$ ): The temperature at which the stabilizer works primarily depends on the alcohol content of the wine, but this usually varied between -4.5 and $-5{ }^{\circ} \mathrm{C}$. In this case, the measurements were performed over white wines.

e) Diatomaceous earth filtration: A $20 \mathrm{~m}^{2}$ pressure filter (Della Toffola, Italy), with an approximate capacity of $15,000 \mathrm{~L} \mathrm{~h}^{-1}$, was assessed over white wines with temperatures between 10.4 and 10.7 ${ }^{\circ} \mathrm{C}$. The filter was operated with Celite $5 \mathrm{~F}$ for the pre-coat and Celite 505 for dosage during filtration. The turbidity of the tested wines was below 200 NTU.

f) Pad filtration: An IS5 plate filter (Della Toffola, Italy) with 40 AF70 cellulose sheets of 40 by 40 $\mathrm{cm}$ and $1.0 \mu \mathrm{m}$ pore size (Laffort, France) was assessed. The selected red wines had temperatures varying between 10 and $11.1^{\circ} \mathrm{C}$.

g) Tangential flow filtration: An Oenoflow XL-5A filter (Pall Corporation, Italy) with five cross-flow filtration modules $\left(107.5 \mathrm{~m}^{2}\right.$ of filtration area) and a flow rate between 5,000 and $7,500 \mathrm{~L} \mathrm{~h}^{-1}$ was tested. As before, the temperatures of the red wines were between 11 and $11.5^{\circ} \mathrm{C}$.

h) Membrane filtration: A multiple membrane filter housing (Della Toffola, Italy) loaded with five $0.45 \mu \mathrm{m}$ cartridges of a $2.4 \mathrm{~m}^{2}$ filtration area (Vinosart ${ }^{\circledR}$ PS Cartridge 5422506A3, Sartorius) was evaluated over white wines. The initial wine turbidity was below $5 \mathrm{NTU}$, and the temperature ranged between 10 and $11^{\circ} \mathrm{C}$. 
i) Bulk wine transportation: The tanker trailers totaled 30,000 L divided into three compartments with capacities of 5,000, 10,000, and 15,000 L. Caution was taken to fill each compartment up the top. DO measurements were performed after each individual tank was filled and during the unloading of the wine at the destination. The measurements were performed separately over 10 white $\left(12\right.$ to $15^{\circ} \mathrm{C}$ ) and 10 red wines (14 to 17 ${ }^{\circ} \mathrm{C}$ ) that were transported for approximately 200 and $150 \mathrm{~km}$, respectively (approximately 3.5 and $3 \mathrm{~h}$, respectively), with average ambient temperatures of approximately 17 to $19^{\circ} \mathrm{C}$. In the case of white wines, the trailer tanks were treated with 5 to $10 \mathrm{~kg}$ of dry ice each before wine loading. Similarly, the wines were sparged with nitrogen gas (Indura, 99.5\% purity) at a rate of $5 \mathrm{~L} \mathrm{~min}^{-1}$ to avoid an elevated oxygen pickup during the filling process.

\section{Data analysis}

The data were analyzed and arranged using descriptive statistics, and the DO enrichment that occurred during each process was reported (i.e., the arithmetic difference of dissolved oxygen measured before and after a given winery tool). Box plots were used to graphically present the data grouped in quartiles, including variability whiskers representing the observations outside the lower and upper quartiles. The size of the box denotes the interquartile range, the line within the box characterizes the median value, and dots outside the whiskers correspond to outlier observations.

\section{Results}

Most of the equipment and operations assessed yielded moderate or low oxygen enrichments (i.e., below $0.450 \mathrm{mg} \mathrm{L}^{-1}$ ), with the exception of rotary vacuum filtration and continuous tartrate stabilization, where the minimum DO increases were above $1.9 \mathrm{mg} \mathrm{L}^{-1}$, as described below.

a) Centrifugal pumping showed a median oxygen enrichment of $0.049 \mathrm{mg} \mathrm{L}^{-1}$, with an average value of $0.054 \mathrm{mg} \mathrm{L}^{-1}$, a minimum of $0.029 \mathrm{mg} \mathrm{L}^{-1}$ and a maximum of $0.097 \mathrm{mg} \mathrm{L}^{-1}$ (Figure 2). The results showed a greater data dispersion between the 50 th percentile (median) and 100\%.

b) Centrifugation presented a range of DO increments between 0.354 and $0.382 \mathrm{mg} \mathrm{L}^{-1}$, a median value of $0.364 \mathrm{mg} \mathrm{L}^{-1}$ (Figure 2), and an average increase of $0.367 \mathrm{mg} \mathrm{L}^{-1}$. All observations had a very low data dispersion around the median.

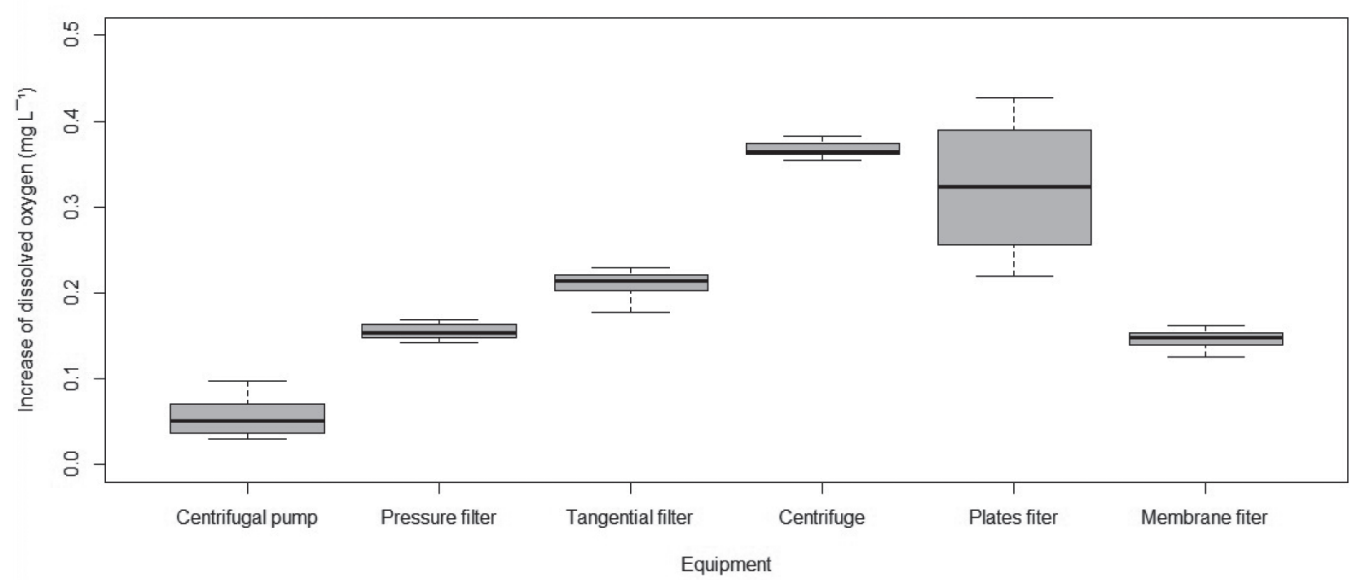

Figure 2. Increase in wine dissolved oxygen as a result of the use of selected winery equipment producing low to moderate oxygen enrichment. 
c) Rotary vacuum filtration displayed an average oxygen increase of $2.250 \mathrm{mg} \mathrm{L}^{-1}$, with minimums and maximums of 1.992 and $2.562 \mathrm{mg} \mathrm{L}^{-1}$, respectively, and a median value of $2.296 \mathrm{mg} \mathrm{L}^{-1}$. The corresponding box plot of Figure 3 shows a wide data dispersion that is much more pronounced from the second quartile above.

d) For continuous tartrate stabilization, the stabilization process is performed at low temperatures (e.g., $-5^{\circ} \mathrm{C}$ ), and significant oxygen dissolution was expected. An average increase of $2.714 \mathrm{mg} \mathrm{L}^{-1}$ of DO was observed, with a range of values between 2.669 and $2.764 \mathrm{mg} / \mathrm{L}$, a median value of 2.723 $\mathrm{mg} \mathrm{L}^{-1}$ and an outlier observation at $2.558 \mathrm{mg} \mathrm{L}^{-1}$ of DO (Figure 3). In this case, the observed DO increases were more dispersed below the median.

e) Diatomaceous earth filtration showed a median oxygen increase of $0.157 \mathrm{mg} \mathrm{L}^{-1}$, with a range of values varying between 0.141 and $0.177 \mathrm{mg} \mathrm{L}^{-1}$ (Figure 2) and an average oxygen increase of $0.155 \mathrm{mg} \mathrm{L}^{-1}$. As observed in Figure 2, all values of oxygen enrichment recorded had a low dispersion around the median.

f) Due to the exposed configuration of the pad filter to ambient air and the variable nature of the filter sheets, moderate amounts of oxygen increases and a wider range of data were expected. Likewise, the measurements conducted showed a median oxygen increase of $0.315 \mathrm{mg} \mathrm{L}^{-1}$, an average oxygen enrichment of $0.331 \mathrm{mg} \mathrm{L}^{-1}$, and a range of observations from 0.219 to $0.428 \mathrm{mg}$ $\mathrm{L}^{-1}$ (Figure 2); a much larger data dispersion than that for diatomaceous earth filtration or tangential flow filtration was observed.

g) Tangential flow filtration presented a median oxygen increase of $0.214 \mathrm{mg} \mathrm{L}^{-1}$, along with an average of $0.210 \mathrm{mg} \mathrm{L}^{-1}$ of DO enrichment. The smallest increase observed was $0.178 \mathrm{mg} \mathrm{L}^{-1}$, whereas the largest value reached $0.229 \mathrm{mg} \mathrm{L}^{-1}$ (Figure 2). Once again, a small variation between the lowest and the highest oxygen increase was observed $\left(0.051 \mathrm{mg} \mathrm{L}^{-1}\right)$.

h) Membrane filtration showed an average oxygen increase of $0.161 \mathrm{mg} \mathrm{L}^{-1}$, a range between 0.125 and $0.165 \mathrm{mg} \mathrm{L}^{-1}$, and a median oxygen enrichment of $0.147 \mathrm{mg} \mathrm{L}^{-1}$ (Figure 2). In this case, the data were slightly more scattered under the 50 th percentile than above the median.

i) For the bulk wine transportation, white wines had a median oxygen increase of $0.147 \mathrm{mg} \mathrm{L}^{-1}$, an average of $0.142 \mathrm{mg} \mathrm{L}^{-1}$, and a range of values from 0.107 to $0.159 \mathrm{mg} \mathrm{L}^{-1}$ that was more dispersed below the median. The range of results observed for red wines was less scattered, but an outlier at $0.265 \mathrm{mg} \mathrm{L}^{-1}$ was also measured (Figure 4). In this case, the median and average oxygen enrichment measured were 0.201 and $0.217 \mathrm{mg}$ $\mathrm{L}^{-1}$, respectively. Surprisingly, the temperature at which the wines were loaded showed minimum variations at the time of unloading $\left(+0\right.$ a $\left.1.5^{\circ} \mathrm{C}\right)$.

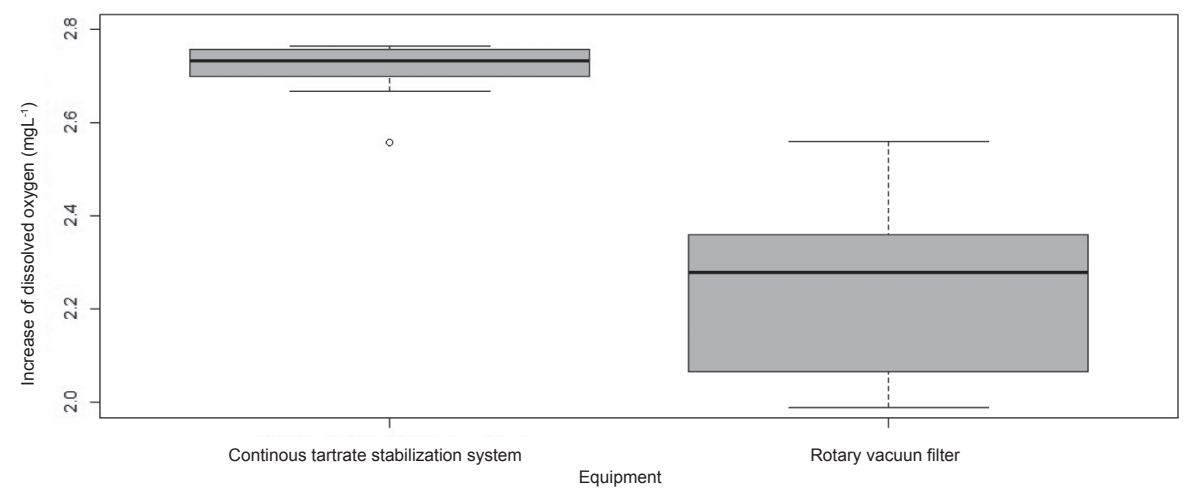

Figure 3. Increase in wine dissolved oxygen as a result of the use of selected winery equipment producing high oxygen enrichment. 


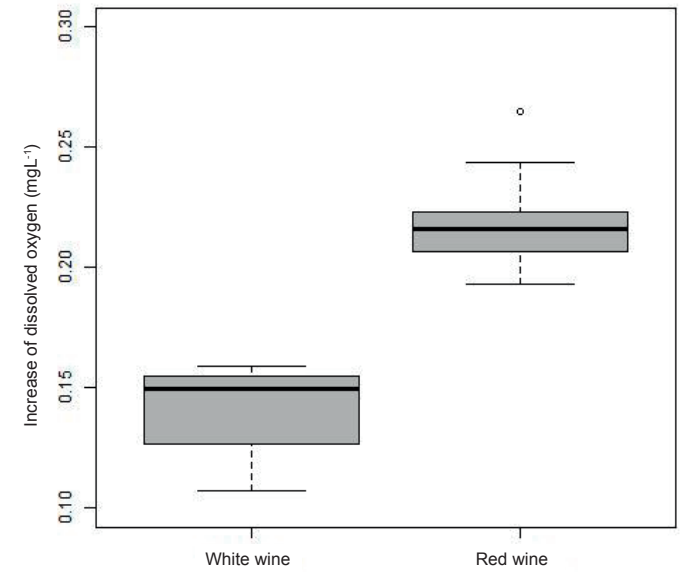

Figure 4. Increase in wine dissolved oxygen as a result of bulk wine transportation in tanker trailers.Discussion

The results of this study showed a wide variation in oxygen incorporation produced by different equipment types and winemaking processes, ranging from a minimal contribution of centrifugal pumps $\left(<0.100 \mathrm{mg} \mathrm{L}^{-1}\right)$ up to large oxygen enrichments observed during continuous tartrate stabilization $\left(\geq 2.559 \mathrm{mg} \mathrm{L}^{-1}\right)$. Several of these results were in agreement with those previously reported elsewhere, in which an electrochemical-based oxygen meter was tested. However, comparing results from different studies should be taken with caution, as -for example- the temperature of the wines varied among different studies. Under constant pressure conditions, the DO concentration decreases exponentially with increasing temperature (Devatine et al., 2007).

In further detail, the following processes are discussed below:

a) Centrifugal pump: Previous results obtained for centrifugal pumps indicated a median oxygen increase of $\sim 0.100 \mathrm{mg} \mathrm{L}^{-1}$ (Castellari et al., 2004) and a range of DO enrichment between 0.100 and $0.200 \mathrm{mg} \mathrm{L}^{-1}$ (Vidal et al., 2001). If the pump rotor or seals are damaged or if the flexible tubing is not connected properly, much larger oxygen enrichments are expected.

b) Centrifuge: The evaluated centrifuge produced a relatively low oxygen increase and low data variability. Our results were within the lower range of values reported elsewhere (Castellari et al., 2004), in which the observed median (1.2 $\left.\mathrm{mg} \mathrm{L}^{-1}\right)$ and data variability were higher. Similarly, the oxygen enrichment observed by Vidal and collaborators was between 0.7 and $1 \mathrm{mg} \mathrm{L}^{-1}$ (Vidal et al., 2001).

c) Rotary vacuum filtration: During this process, the wine is fully exposed to air while in the filter vat, therefore the DO enrichment was expected and confirmed to be much higher than for the other types of filters.

d) Continuous tartrate stabilization: The results obtained were in the lower range of DO enrichment previously reported, in which the median increase observed was slightly higher than $4 \mathrm{mg}$ $\mathrm{L}^{-1}$ (Castellari et al., 2004). Likewise, the results reported by Vidal and collaborators averaged $2.380 \mathrm{mg} \mathrm{L}^{-1}$ during continuous operation (Vidal et al., 2003), reaching values close to the oxygen saturation (i.e., $6 \mathrm{mg} \mathrm{L}^{-1}$ ) if the entire process, including pumping, is considered. Clearly, if this procedure is not optimized, and no measures are taken to strip oxygen before consumption (e.g., by means of the use of inert gases), the likelihood of experiencing wine oxidation or microbial spoilage increases.

e) Diatomaceous earth filtration: The low variability of the results could be because in all cases, the same protocol for pre-coat preparation and filter operation was used. In addition, all wines filtered had equivalent initial turbidity levels ( $<200$ NTU). Similar to the results of this study, the median oxygen enrichment previously reported for this type of filter was between 0.200 and $0.250 \mathrm{mg}$ $\mathrm{L}^{-1}$ (Vidal et al., 2001; Castellari et al., 2004).

f) Pad filtration: This type of filtration showed a larger relative variability compared to the other filtration and centrifugation equipment tested, and the oxygen enrichment observed was higher than that reported by Castellari et al. (2004), in which the oxygen increase was below $0.150 \mathrm{mg} \mathrm{L}^{-1}$. The 
differences observed could be due to temperature variations (i.e., 15 to $20^{\circ} \mathrm{C}$ in the case of Castellari et al., 2004) or dissimilar processing. In fact, an oxygen enrichment of $0.45 \mathrm{mg} / \mathrm{L}$ with this type of filter, but under different operating conditions, has also been reported (Vidal et al., 2004).

g) Tangential flow filtration: In the case of crossflow filters with a larger number of modules, or wines with a high initial turbidity, more oxygen dissolution is expected due to the continual recycling of wine through the cross-flow membranes. In this case, the initial turbidity of all wines was below 150 NTU. Our results were within the range of values reported by Castellari et al. (2004), in which a median of approximately $0.2 \mathrm{mg} \mathrm{L}^{-1}$ was observed. Similarly, Vidal and collaborators found oxygen increases during continuous operation varying from 0.15 to $0.8 \mathrm{mg} \mathrm{L}^{-1}$ (Vidal et al., 2001).

h) Membrane filtration: Previous results demonstrated median values below $0.1 \mathrm{mg} \mathrm{L}^{-1}$ (Castellari et al., 2004) and between 0 and $0.3 \mathrm{mg} \mathrm{L}^{-1}$ (Vidal et al., 2004). Evidently, the oxygen enrichment as a result of this type of filter should be low because they are usually the last filter used before wine bottling.

i) Bulk wine transportation: The lower oxygen incorporation observed in white wines may be because both the liquid and truck compartments received inert gases to help reduce oxygen pickup during loading on the truck. Previous results from studies performed elsewhere (Vidal et al., 2001), which used a limited number of trucks and only indicated the DO at the final destination, show that if the trailer compartments are not filled to the top, much larger DO levels are observed (i.e., $1.4 \mathrm{mg}$ $\mathrm{L}^{-1}$ of DO for semi-full containers vs. $0.4 \mathrm{mg} \mathrm{L}^{-1}$ of DO for full containers). In addition, it should be noted that in both cases, the measurements performed did not account for the consumption of oxygen that could have occurred during transport, which is known to be a slow process. For example, after saturating a red wine with oxygen (6 mg of oxygen $\mathrm{L}^{-1}$ ), approximately $1 \mathrm{mg} \mathrm{L}^{-1}$ is consumed every six days at a temperature of 30 ${ }^{\circ} \mathrm{C}$ (Singleton, 1987).

In conclusion, different winemaking equipment types and operations were evaluated, distinguishing those capable of incorporating significant amounts of oxygen into wines, such as rotary vacuum filtration and continuous tartrate stabilization. Further research in this area should include other common winemaking practices, as well as an evaluation of the effectiveness of different means to reduce the concentration of dissolved oxygen in wines (i.e., treatments with sulfur dioxide and inert gases).

\section{Acknowledgments}

This research was funded by Conicyt Chile through Fondecyt grant 1110655 and the Spanish Government through project AGL2011-26931. Our thanks to Mario Miranda and Marcio Ramírez from Viña Concha y Toro, and Matías Melnick from Vitivinícola Patacón (Chile) for allowing access to the wineries in which the data were collected.

\section{Resumen}

J.F. Calderón, M. del Alamo-Sanza, I. Nevares y V.F. Laurie. 2014. Efecto de diferentes equipos y operaciones de vinificación sobre la concentración de oxígeno disuelto en vinos. Cien. Inv. Agr. 41(2): 273-280. El oxígeno tiene un efecto determinante en la calidad y la longevidad de los vinos. A pesar de su importancia, existe solo un número limitado de investigaciones donde se analice la concentración de oxígeno disuelto durante la producción de vinos y los efectos de diferentes prácticas de vinificación sobre dichos niveles. En este estudio, se evaluó la contribución de diversos equipos y prácticas de vinificación (ej. 
bombeo, centrifugado, estabilización tartárica, filtración y transporte del vino a granel) sobre la concentración de oxígeno disuelto en vinos, utilizando un medidor de oxígeno basado en el principio de fotoluminiscencia. Por ejemplo, equipos de soporte a la elaboración de vino tales como filtros de tierras diatomeas y filtros de membranas produjeron de entre 0,100 hasta $0,200 \mathrm{mg} \mathrm{L}^{-1}$, la filtración por placas y la centrifugación mostró enriquecimientos promedio de oxígeno de alrededor de $0,350 \mathrm{mg} \mathrm{L}^{-1}$, mientras que el uso de filtros rotatorios al vacío y equipos de estabilización tartárica continua produjeron enriquecimientos de oxígeno de hasta $\sim 2,8 \mathrm{mg} \mathrm{L}^{-1}$. Un mejor conocimiento de los niveles de oxígeno incorporadas por las diferentes prácticas enológicas ayudará a tomar las salvaguardias necesarias para proteger los vinos de las oxidaciones y estimar la magnitud de la exposición acumulativa al oxígeno durante la elaboración del mismo.

Palabras clave: Fotoluminiscencia, medidor de oxígeno, oxígeno disuelto, vino.

\section{References}

Castellari, M., B. Simonato, G.B. Tornielli, P. Spinelli, and R. Ferrarini. 2004. Effects of different enological treatments on dissolved oxygen in wines. Italian Journal of Food Science 16:387396.

Danilewicz, J.C. 2003. Review of reaction mechanisms of oxygen and proposed intermediate reduction products in wine: Central role of iron and copper. American Journal of Enology and Viticulture 54:73-85.

Devatine, A., I. Chiciuc, C. Poupot, and M. MiettonPeuchot. 2007. Micro-oxygenation of wine in presence of dissolved carbon dioxide. Chemical Engineering Science 62:4579-4588.

Laurie, V.F., and A.C. Clark. 2010. Wine Oxidation. In: E.A. Decker, R.J. Elias, and D.J. McClemens (eds.). p. 445-475. Oxidation in foods and beverages and antioxidant applications. Volume 2: Management in different industry sectors. Woodhead Publishing Co.

Ough, C.S., and M.A. Amerine. 1988. Methods for Analysis of Musts and Wines. Wiley, New York.
Singleton, V.L. 1987. Oxygen with Phenols and Related Reactions in Musts, Wines, and Model Systems: Observations and Practical Implications. American Journal of Enology and Viticulture 38:69-77.

Vidal, J.C., J.C. Boulet, and M. Moutounet. 2003. Les apports d'oxygène au cours des traitements des vins. Bilan des observations sur site. 2éme partie. Revue Française d'Oenologie 201: 32-38.

Vidal, J.C., J.C. Boulet, and M. Moutounet. 2004. Les apports d'oxygène au cours des traitements des vins. Bilan des observations sur site. 3ème partie. Revue Française d'Oenologie 205:25-33.

Vidal, J.C., T. Dufourcq, J.C. Boulet, and M. Moutounet. 2001. Les apports d'oxygène au cours des traitements des vins. Bilan des observations sur site, 1ère partie. Revue Française d'Oenologie 190:24-31.

Waterhouse, A.L., and V.F. Laurie. 2006. Oxidation of wine phenolics: A critical evaluation and hypotheses. American Journal of Enology and Viticulture 57:306-313. 